Article

\title{
Rheology-Microstructure Relationships in Melt-Processed Polylactide/Poly(vinylidene Fluoride) Blends
}

\author{
Reza Salehiyan ${ }^{1, *}$, Suprakas Sinha Ray ${ }^{1,2, * \mathbb{D}}$, Florian J. Stadler ${ }^{3}$ and Vincent Ojijo ${ }^{1}$ \\ 1 DST-CSIR National Centre for Nanostructured Materials, Council for Scientific and Industrial Research, \\ Pretoria 0001, South Africa; VOjijo@csir.co.za \\ 2 Department of Applied Chemistry, University of Johannesburg, Doorfontein, Johannesburg 2028, \\ South Africa \\ 3 College of Materials Science and Engineering, Shenzhen Key Laboratory of Polymer Science and Technology, \\ Guandong Research Center for Interfacial Engineering of Functional Materials, Nanshan District Key Lab \\ for Biopolymers and Safety Evaluation, Shenzhen University, Shenzhen 518055, China; fjstadler@szu.edu.cn \\ * Correspondence: RSalehiyan@csir.co.za (R.S.); rsuprakas@csir.co.za (S.S.R.); Tel.: +27-12-841-2388 (S.S.R.)
}

Received: 1 October 2018; Accepted: 7 November 2018; Published: 3 December 2018

\begin{abstract}
In this study, small amplitude oscillatory shear tests are applied to investigate the rheological responses of polylactide/poly(vinylidene fluoride) (PLA/PVDF) blends and to correlate their viscoelastic properties with the morphological evolutions during processing. Although the analysis of the elastic moduli reveals some changes as a function of blend composition and processing time, the weighted relaxation spectra are shown to be more useful in detecting changes. The analysis demonstrates that when PVDF, i.e., the more viscous phase, is the matrix, the blend relaxes cooperatively and only a single relaxation peak is observed. By contrast, blends with highly concentrated morphologies do not fully relax, showing instead an upward increasing trend at longer times. This outcome is attributed to the broad distribution of highly concentrated droplets with a high probability of droplet-droplet contacts. Dynamic mechanical analysis (DMA) reveals that crystalline segmental motions attributed to the $\alpha$-relaxation of PVDF at around $100{ }^{\circ} \mathrm{C}$ are restricted by the highly concentrated morphology of the 50/50 PLA/PVDF blend processed for $10 \mathrm{~min}$. Relaxation analyses of the blends via dynamic oscillatory shear tests and DMA are shown to be powerful tools for investigating small microstructural changes in immiscible polymer blends.
\end{abstract}

Keywords: PLA/PVDF blend; rheology; processing-driven morphology

\section{Introduction}

The blending of two or more polymers is an economically efficient strategy for the development of materials with interesting characteristics. However, most chemically different polymers are immiscible, and their blending leads to phase-separated morphologies with weak interfacial adhesion and thus poor mechanical performances. [1]. Since the final properties of the blends are directly dependent on the morphologies, many attempts have been made to tune the morphologies towards the desired application. The studies reported to date have shown that various morphologies can be developed by simply altering the dynamic and kinetic parameters, such as the blend ratio [2-4], the viscosity ratio [5], compatibilization [6-8], the mixing time [9,10], and the mixer type [11,12]. In recent years, the interest in bio-based polymer blends as alternatives to fuel-based ones has been growing as a result of the environmental issues that are associated with fuel-based blends [13]. Among the bio-based polymers available, polylactide (PLA) has attracted significant attention owing to its green characteristics (bio-degradable and biomedical) and reasonable modulus. However, its brittleness 
and slow crystallization rate have limited its application and processability $[14,15]$. Thus, PLA has been blended with other polymers with higher flexibility and lower rigidity to overcome such challenges [14,16-20]. In the previous study [21], an important benefit was found by blending PLA with poly(vinylidene fluoride) (PVDF); specifically, the addition of PVDF promoted the crystallization of PLA; for example, the mixing of $30 \mathrm{wt} \%$ of PLA with $70 \mathrm{wt} \%$ of PVDF for $10 \mathrm{~min}$ resulted in the formation of $\beta$-phase crystals. This result indicates the importance of morphological changes on the final properties of the blends.

The rheological properties of this particular blend have been studied previously [22,23]. Wang et al. [23] studied the rheological properties of the compatibilized and uncomaptibilized poly(L-lactic acid) (PLLA)/PVDF blends at different ratios via small amplitude oscillatory shear (SAOS) tests. As expected, the viscoelastic properties of the blends increased when the loading of the high-molecular-weight PVDF was increased. In their study, the authors reported a co-continuous morphology at a (65/35) PVDF/PLLA blend ratio, where the longest relaxation time ascribed to the relaxation of the droplets did not appear as a peak. In another study, Xie et al. [22] investigated the SAOS behavior of PVDF-rich PLA/PVDF blends with a maximum of $20 \mathrm{wt} \%$ of PLA. This work showed that increasing the PLA content from 5 to $15 \mathrm{wt} \%$ increases the elastic modulus as a result of the increased interfacial interactions between PVDF and PLA.

In the current work, for the first time, the rheological properties of PLA/PVDF blends were investigated exclusively with respect to the morphological changes occurring as a function of processing time and ratios in both PLA-rich and PVDF-rich compositions. The findings from the previous study [21] revealed that morphologies and properties are not determined solely by the composition ratios but also by the processing time, which can alter the properties particularly when the blends are not compatibilized. Therefore, rheological tools were utilized to identify the extent of the morphological changes induced by the processing conditions. The dependency of the droplet coalescence-breakup cycle on the viscosity ratio of the blends has been discussed. Continuous relaxation spectra of the blends were employed to analyze the morphological evolutions of the blends and droplet deformations and understand the influence of microstructural changes on the molecular dynamics of the blends. The results of this study will make a significant contribution to the literature because it demonstrates that experimental conditions, such as processing time and composition ratio, can be used to alter the properties of immiscible polymer blends.

\section{Materials and Methods}

\subsection{Materials}

Both the PLA and PVDF polymers used in this study were of commercial grade. The 7032D PLA (melt-flow index (MFI) $=13.81 \mathrm{~g} / 10 \mathrm{~min}$ at $190^{\circ} \mathrm{C}$ and $2.16 \mathrm{~kg}$ load), with a specific gravity of 1.24, was purchased from NatureWorks, LLC (Minnetonka, MN, USA). PVDF (MFI = 2.2 g/10 min at $300{ }^{\circ} \mathrm{C}$ and $3.8 \mathrm{~kg}$ load), with a density of $1.74 \mathrm{~g} / \mathrm{cm}^{3}$ at $20^{\circ} \mathrm{C}$, was obtained from SynQuest Labs., Inc. (Alachua, FL, USA). The MFI values per conditions shown indicate the very high viscosity of PVDF when compared to PLA. Both polymers have similar melting point ranges $\left(155-170{ }^{\circ} \mathrm{C}\right)$ according to the suppliers and findings from a previous study [21].

\subsection{Processing}

Pellets of PLA and PVDF were kept in a vacuum oven at a temperature of $70{ }^{\circ} \mathrm{C}$ for about $12 \mathrm{~h}$ prior to mixing in order to remove excess moisture. The dried hand-mixed ratios (70/30; 50/50; and 30/70) of PLA/PVDF mixtures were melt-blended in HAAKE PolyLab OS Rheomix (Thermo Fisher Scientific, Dreieich, Hessen, Germany) at a rotor speed of $60 \mathrm{rpm}$ and a temperature of $190{ }^{\circ} \mathrm{C}$ for 5, 7.5, and $10 \mathrm{~min}$. Subsequently, the blends were compression-molded using a Carver Laboratory hot press (Wabash, IN, USA) at $190^{\circ} \mathrm{C}$ and cooled to room temperature to prepare discs with a diameter of $25 \mathrm{~mm}$ for rheological characterization. 


\subsection{Rheometry}

Samples were annealed at $60^{\circ} \mathrm{C}$ for $12 \mathrm{~h}$ before the rheological characterization in order to avoid the effects of moisture trapped in the bulk of the samples on the results. A Physica MCR501 rheometer (Anton Paar, Graz, Austria) with 25-mm-diameter parallel plates was used to perform rheological analyses under a nitrogen environment. SAOS tests were carried out for frequencies ranging from low $(0.01 \mathrm{rad} / \mathrm{s})$ to high $(100 \mathrm{rad} / \mathrm{s})$ at a fixed strain of $0.5 \%$ (linear region) and a temperature of $200{ }^{\circ} \mathrm{C}$.

\subsection{Determination of Continuous Relaxation Spectra}

The continuous relaxation spectra were determined according to the method reported by Stadler and Bailly [24], which, unlike all other methods, does not calculate the spectrum directly but instead optimizes $n$ spectra descriptors-knots of a Hermite spline-which are subsequently used to determine the spectrum in the form of a Hermite spline, and used to reconstruct the input data $\left(G^{\prime}(\omega)\right.$ and $\left.G^{\prime \prime}(\omega)\right)$ from the spectrum as follows:

$$
\begin{gathered}
G^{\prime}(\omega)=G_{\infty}+\sum_{i=1}^{n} g_{i}\left(\tau_{i}\right) \cdot\left(\frac{\omega^{2} \cdot \tau_{i}^{2}}{1+\omega^{2} \cdot \tau_{i}^{2}}\right)=G_{\infty}+\int_{0}^{\infty} H(\tau) \cdot\left(\frac{\omega^{2} \cdot \tau^{2}}{1+\omega^{2} \cdot \tau^{2}}\right) d \ln \tau \\
G^{\prime \prime}(\omega)=\sum_{i=1}^{n} g_{i}\left(\tau_{i}\right) \cdot\left(\frac{\omega \cdot \tau_{i}}{1+\omega^{2} \cdot \tau_{i}^{2}}\right)=\int_{0}^{\infty} H(\tau) \cdot\left(\frac{\omega \cdot \tau}{1+\omega^{2} \cdot \tau^{2}}\right) d \ln \tau
\end{gathered}
$$

The spectrum descriptors and, consequently, the spectrum were optimized using a pursuit algorithm to minimize the least mean square error $D^{2 *}$ according to the formula reported by Baumgärtel and Winter [25], with the addition of the slope penalty $s$ :

$$
D^{2 *}=\sqrt{\frac{1}{n} \sum_{i=1}^{n}\left[\left(\frac{G_{i}^{\prime}-G_{i \mathrm{fit}}^{\prime}}{G_{i}^{\prime}}\right)^{2}+\left(\frac{G_{i}^{\prime \prime}-G_{i \mathrm{fit}}^{\prime \prime}}{G_{i}^{\prime \prime}}\right)^{2}\right]}+s
$$

which forbids excessively large slopes, and is defined as:

$$
\begin{gathered}
s=\int_{\tau_{i-1}}^{\tau_{i}} z d \tau, \\
\text { with } Z(\tau)=10, \text { if } \frac{d \log H}{d \log \tau}(\tau)>m, \\
\text { and } Z(\tau)=0, \text { if } \frac{d \log H}{d \log \tau}(\tau) \leq m
\end{gathered}
$$

with $m$ being set to 2, i.e., a value that reliably avoids excessive slopes and at the same time will not influence the spectrum. This slope penalty was shown to avoid unphysical solutions arising from the pursuit algorithm getting stuck in local minima of $D^{2 *}$.

In order to properly model the data, we first determined the range of relaxation times that has a significant influence on the input data by varying the relaxation time range in which the spectrum is calculated, which was subsequently analyzed using the integrals of the relevance factors as defined previously [26]. After pre-tests, we found that the spectrum can be determined successfully in a range that is one order of magnitude higher than the input data and the input data can be very successfully described with the determined spectrum; hence, an inverse input data interval plus one decade in each direction was used for all calculations presented here.

\subsection{Morphological Analysis}

The morphologies of the blends were studied using a Carl Zeiss Auriga (Oberkochen, Germany) scanning electron microscope (SEM) on cryo-fractured surfaces of the molded samples. The number average $\left(R_{n}\right)$ and volume average $\left(R_{v}\right)$ droplet sizes and size distributions were calculated according to Equations (5)-(7), respectively. The radii of over 100 droplets were calculated for each sample from 
three different images using the image analysis software ImageJ (1.46r, National Institute of Health, Bethesda, MD, USA).

$$
\begin{gathered}
R_{n}=\frac{\sum n_{i} R_{i}}{\sum n_{i}} \\
R_{v}=\frac{\sum n_{i} R_{i}^{4}}{\sum n_{i} R_{i}^{3}} \\
D=\frac{R_{v}}{R_{n}}
\end{gathered}
$$

In which $n_{i}$ is the number of droplets with radius $R_{i}$.

\subsection{Dynamic Mechanical Analysis}

A PerkinElmer dynamic mechanical analyzer (DMA, Waltham, MA, USA) 8000 was used in a single bending mode to carry out the dynamic mechanical analysis of the 10-min-processed blends. Thin films of the (29-30 mg) samples were placed inside the solid steel material pockets. The modulus and $\tan \delta$ of the blends were measured from -60 to $140{ }^{\circ} \mathrm{C}$ at a rate of $2{ }^{\circ} \mathrm{C} / \mathrm{min}$, a frequency of $1 \mathrm{~Hz}$, and a strain amplitude of $0.05 \%$.

\section{Results}

\subsection{Small Amplitude Oscillatory Shear Tests}

Figure 1 shows the elastic moduli $G^{\prime}(\omega)$ of the neat polymers and polymer blends of different compositions and processing times. It is apparent that neat PLA follows the terminal behavior with a power law slope of 2 (for simplicity, the slopes are always mentioned as apparent slopes in the scaling, in which they are plotted, i.e., Figure 1a shows a power law slope of $2\left(\mathrm{~d} \log G^{\prime} / \operatorname{dlog} \omega=2\right)$, which is referred to as slope of 2). The loss moduli $G^{\prime \prime}(\omega)$ and complex viscosities $\left|\eta^{*}(\omega)\right|$ of the blends are detailed in the Supplementary (Figures S1 and S2, respectively). By contrast, PVDF deviates remarkably from such classical behavior, which is indicative of a very large elasticity and a slow relaxation process. These observations are most likely related to the chain mobilities of the polymers. As will be discussed later (see the Section on DMA), PVDF has a glass transition temperature ( $\beta$-relaxation) of around $-30^{\circ} \mathrm{C}$. The weighted relaxation spectra of the polymers and blends also demonstrated the long relaxation mechanism of PVDF and PVDF-rich blends (see the Section on relaxation spectra). As shown (Figure 1), the responses of all of the blends were somewhere between those of the two neat polymers, obeying the simple rule of mixtures. It is interesting to observe the differences in morphological changes during the processing in a blend at a fixed composition (Figure 2). Such morphology development can be explained by the mechanism of droplet deformation during the processing. It is known that the final morphology of an immiscible polymer blend is governed by the balance between droplet breakage and coalescence $[27,28]$. That is, both droplet collision and deformation occur during the mixing process concurrently [29]. Figure 1 shows that this phenomenon also depends on the composition ratio. In the case of the 70/30 PLA/PVDF blends (Figure 1b), the storage modulus $G^{\prime}(\omega)$ is higher when the blend is processed for $5 \mathrm{~min}$. Processing of the blend for a further $2.5 \mathrm{~min}$ (overall $7.5 \mathrm{~min}$ ) decreased the modulus to its minimum value. This result is caused by the fact that highly viscous PVDF droplets are less likely to break further at this point, and, hence, droplets collide to form bigger droplets. The formation of larger droplets is accompanied by a decrease in the modulus. Eventually, the processing for $10 \mathrm{~min}$ allowed the coalesced droplets to break up again, which manifested in a slight increase in the modulus. On the other hand, in the case of 50/50 PLA/PVDF blends, the optimized processing time was established as $7.5 \mathrm{~min}$. Since the two phases are present in equal amounts, one can expect larger domains, and, hence, different collision-breakup frequencies. Finally, increasing the viscosity of the matrix by changing the blend ratio to 30/70 PLA/PVDF has reduced the breakup time; consequently, the subsequent collisions 
also occurred faster. For this reason, the differences observed for the blend with a 50/50 composition as a function of processing time were less obvious. In order to develop a better understanding of these differences, the moduli of the blends normalized relative to the moduli of the 5-min-processed blends were plotted as a function of processing time for a fixed frequency of $0.1 \mathrm{rad} / \mathrm{s}$ (Figure 1e). Since the differences are more significant at longer times (lower frequency regions), the moduli at $0.1 \mathrm{rad} / \mathrm{s}$ were selected to observe the changes as a function of processing time. From Figure 1e, it can be observed that the changes become more significant as the PLA concentration increases. That is, when hard spheres of PVDF exist as the minor dispersed phase within the PLA matrix, the probability of coalescence is higher; or, in other words, the coalescence-breakup cycle is quite slow. By contrast, when PLA is the minor phase within the PVDF matrix, the break-up into smaller droplets occurs more readily, and these can again coalesce into bigger droplets since the blend is not compatibilized. Therefore, a shorter coalescence-breakup cycle can be expected, and consequently, the changes observed are less significant. The results are in agreement with the SEM images of the blends, shown in Figure 2. It must be noted that all of the studied blend ratios exhibited a droplet-matrix morphology. The number average $\left(R_{n}\right)$ and volume average $\left(R_{v}\right)$ droplet radii sizes of the blends are shown in Figure $3 \mathrm{a}, \mathrm{b}$, respectively.

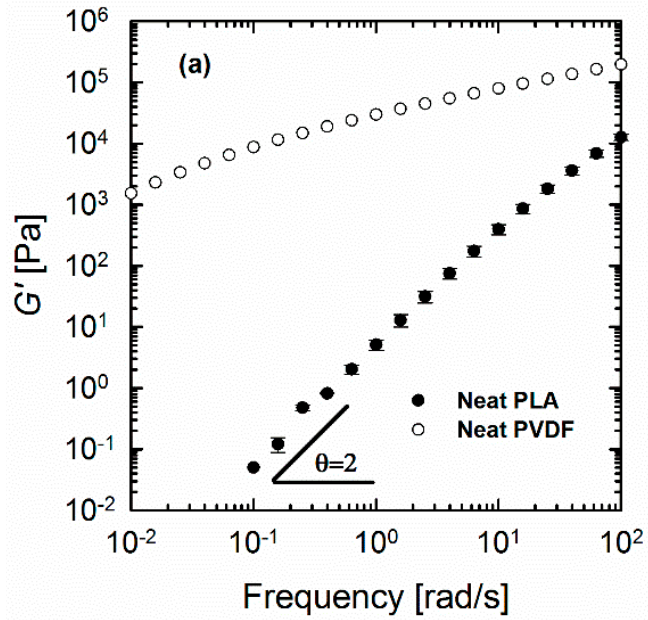

(a)

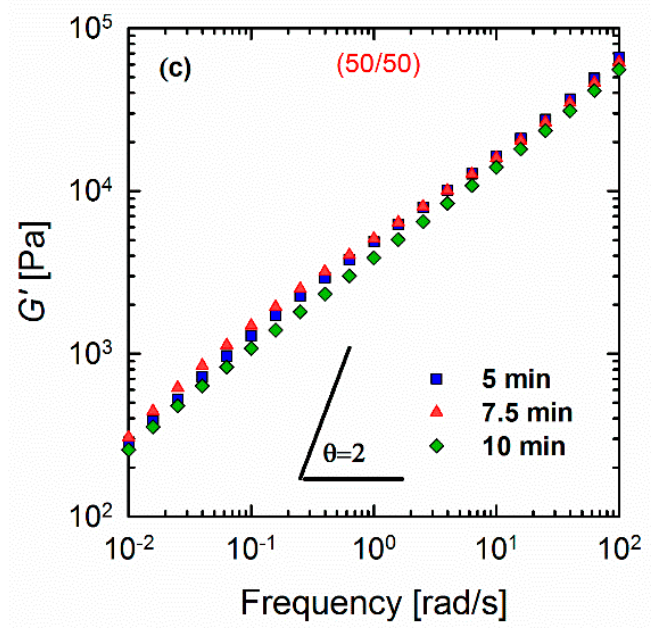

(c)

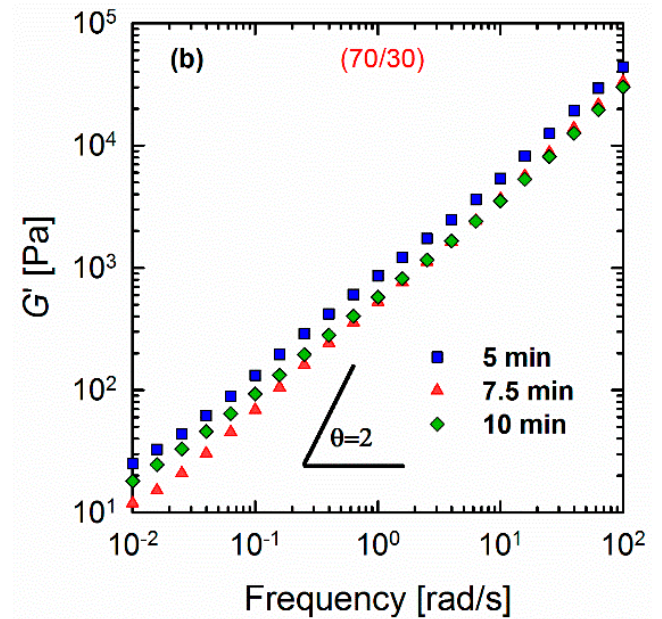

(b)

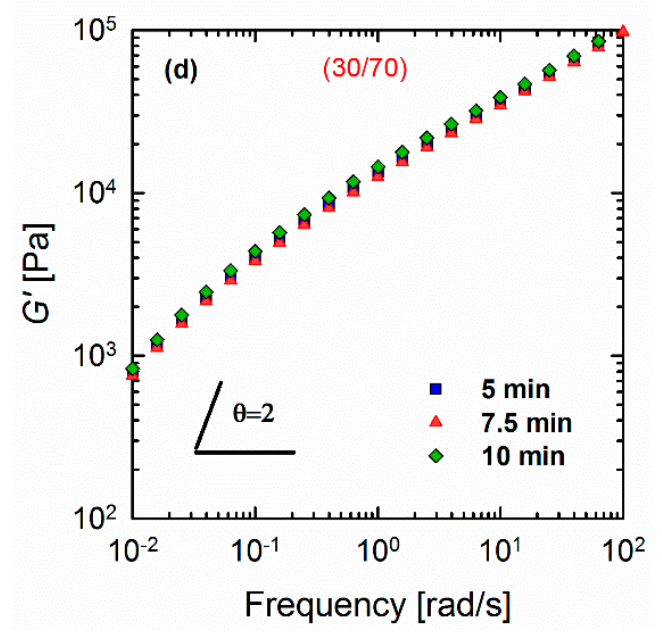

(d)

Figure 1. Cont. 


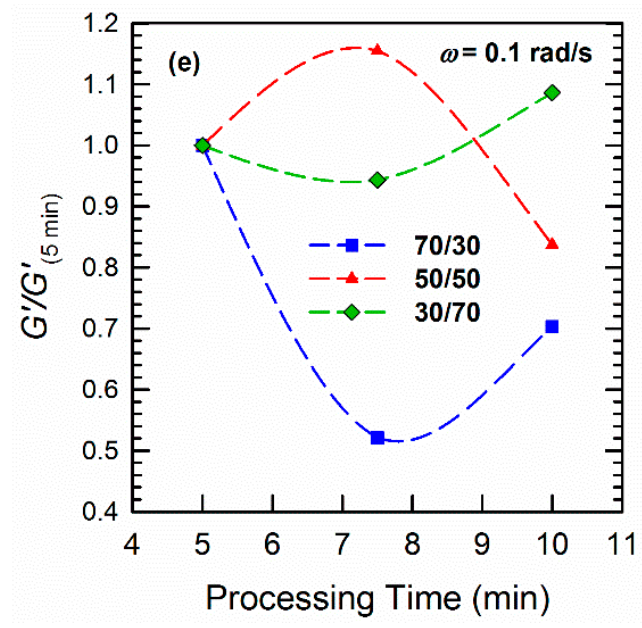

(e)

Figure 1. Storage moduli $G^{\prime}(\omega)$ of (a) neat polymers and (b) 70/30, (c) 50/50, and (d) 30/70 PLA/PVDF blends processed for different times as a function of frequency from 0.01 to $100 \mathrm{rad} / \mathrm{s}$ at strain amplitude of $0.5 \%$ and a temperature of $200{ }^{\circ} \mathrm{C}$ under a nitrogen atmosphere; (e) storage moduli of the blends normalized relative to the storage moduli of the blends processed for $5 \mathrm{~min}$ at a fixed frequency of $0.1 \mathrm{rad} / \mathrm{s}$.
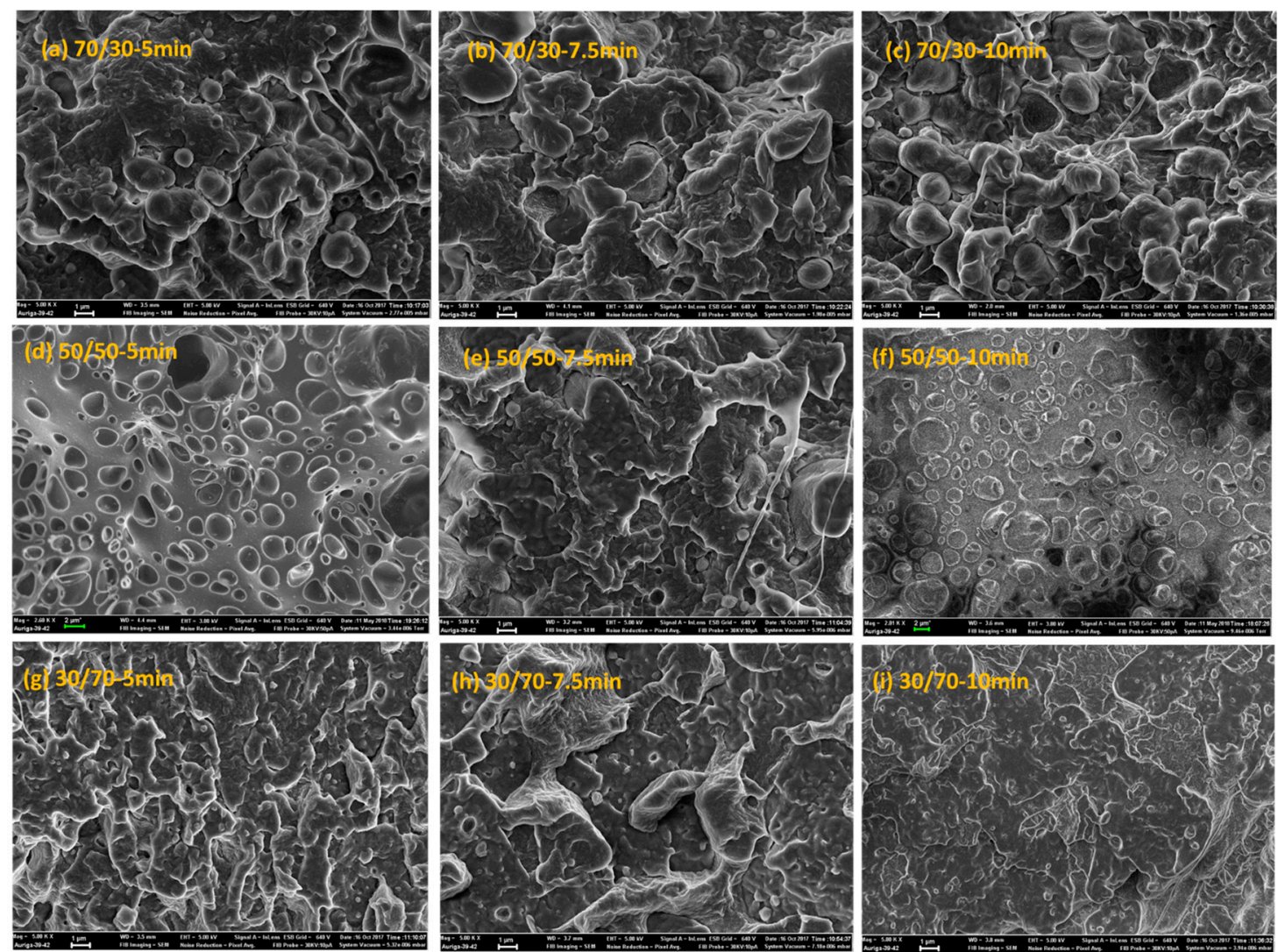

Figure 2. SEM images of (a-c) 70/30, (d-f) 50/50, and (g-i) 30/70 PLA/PVDF blends processed for $(\mathbf{a}, \mathbf{d}, \mathbf{g}) 5 \mathrm{~min},(\mathbf{b}, \mathbf{e}, \mathbf{h}) 7.5 \mathrm{~min}$, and $(\mathbf{c}, \mathbf{f}, \mathbf{i}) 10 \mathrm{~min}$. Scale bars are always equal to $1 \mu \mathrm{m}$, with the exception of $(\mathbf{d}, \mathbf{f})$, where the scale bars indicate $2 \mu \mathrm{m}$. This figure is reprinted with permission from [21]. 


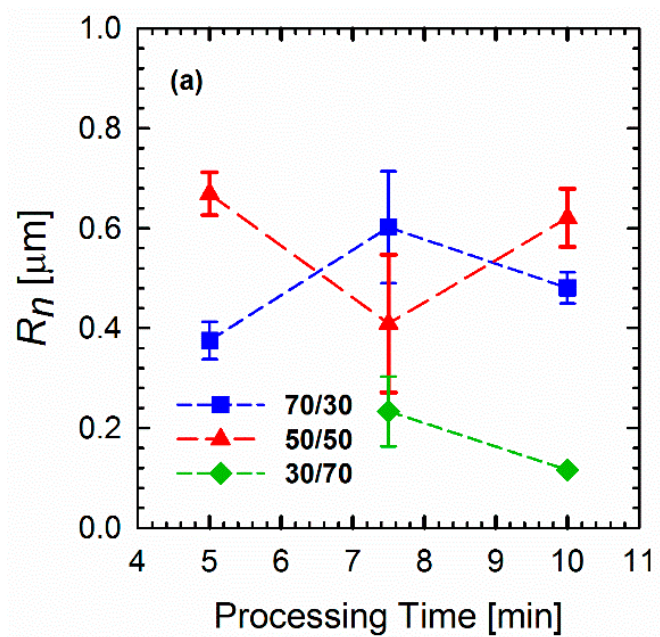

(a)

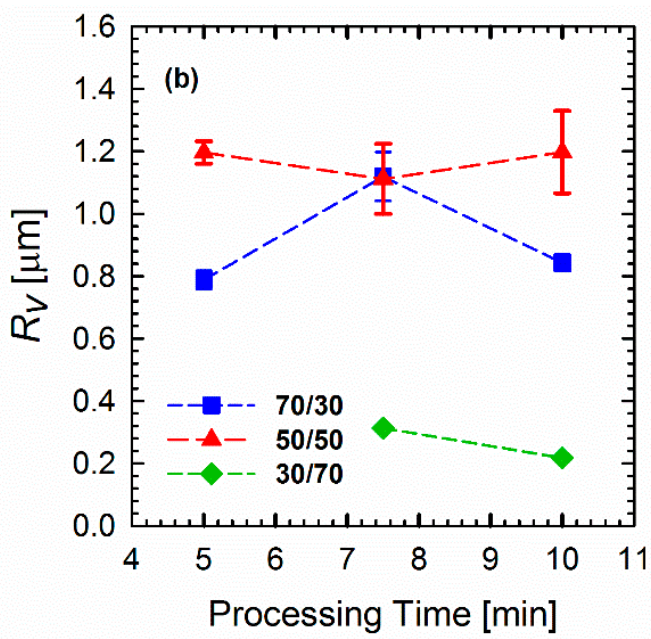

(b)

Figure 3. (a) Number average $\left(R_{n}\right)$ and (b) volume average $\left(R_{v}\right)$ radii sizes of droplets in blends of various compositions calculated based on Equations (5) and (6) from SEM images. The 30/70 PLA/PVDF blend processed for $5 \mathrm{~min}$ did not show a distinct droplet morphology, and, hence, the calculations for this composition were done after processing for 7.5 and 10 min only.

\subsection{Van Gurp-Palmen Plots}

The plots of phase angle $\delta$ as a function of absolute complex modulus $\left|G^{*}(\omega)\right|$, also known as van Gurp-Palmen plots (Figure 4), can also be considered as a complementary tool to investigate the morphology of the polymer blends [30-32]. From these plots, it is clear that PLA exhibits behavior that is typical for linear polymers, where the value of the phase angle $\delta$ reaches a plateau region $\left(90^{\circ}\right)$ at lower $\left|G^{*}(\omega)\right|$ values. By contrast, PVDF shows an immediate decrease in $\delta$ values starting around $60^{\circ}$; this decrease continues until a $\delta$ of $\sim 35^{\circ}$, at which point a small hump with higher $\left|G^{*}(\omega)\right|$ values is observed (Figure 4a). This behavior could be caused by the much higher viscosity and entanglement of the PVDF, which mean that it did not fully relax. It has also been reported previously that a valley at low $\left|G^{*}(\omega)\right|$ values indicates a droplet-matrix morphology, while a maximum at low $\left|G^{*}(\omega)\right|$ regions is a sign of co-continuous morphology [30]. However, Lopez-Baron and Macosko [31] showed that this rule may not be applicable to all systems. The current vGP plots (Figure $4 \mathrm{~b}-\mathrm{d}$ ) revealed shapes that are completely different from those present in previously reported studies; this discrepancy probably stems from the complex structure of PVDF. The blends (particularly the 70/30 and 50/50 PLA/PVDF blends) showed bimodal behavior, where two distinct peaks can be observed. This phenomenon can be related to the relaxation of each phase. In the case of the 70/30 PLA/PVDF blend, the peaks are quite distinct and correspond to the distribution of PVDF droplets in the PLA matrix. Further, the first maximum in the case of the 50/50 blend has decreased at $7.5 \mathrm{~min}$, and faded completely after $10 \mathrm{~min}$, which indicates the long relaxation of PVDF associated with very low frequencies. This result is in accordance with the relaxation spectra of the blends, and could be related to the highly close-packed morphology (i.e., the high concentration of droplets) of this 50/50 blend, as evidenced by the SEM images. In the case of the 30/70 PLA/PVDF blend, the $\delta$ values decreased monotonically on going from $55^{\circ}$ to $38^{\circ}$ (valley area), and subsequently exhibited a small hump related to the relaxation of the PLA phase. This hump again confirms the complexity of the morphologies of this particular blend and the dominance of PVDF relaxation in PVDF-rich blends. 


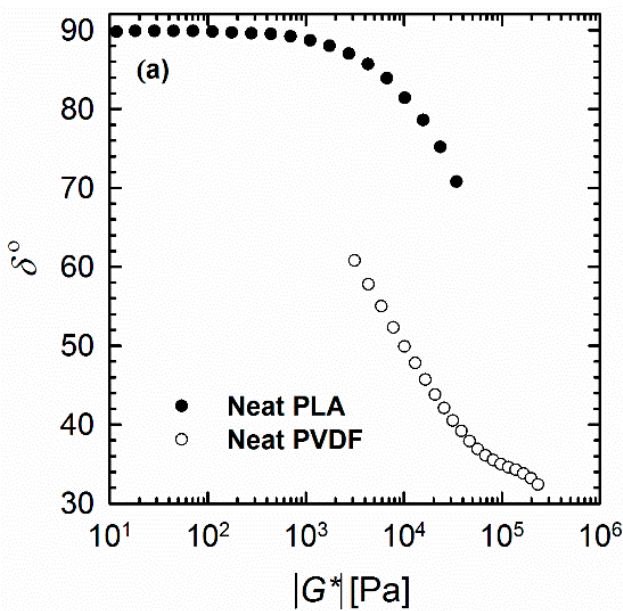

(a)

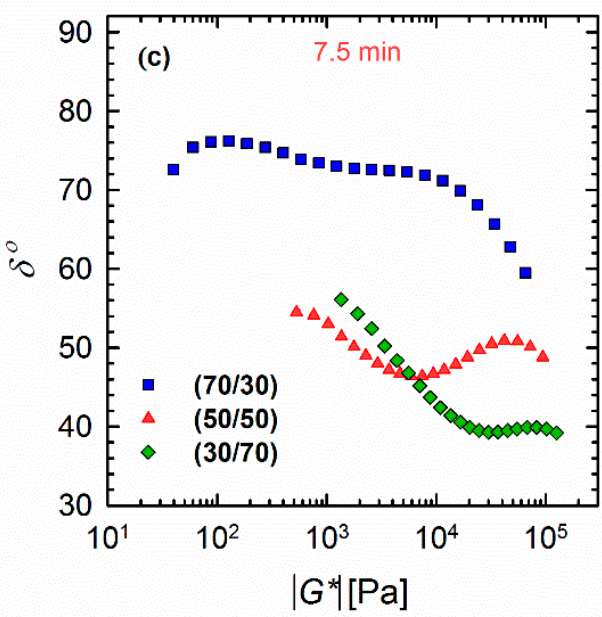

(c)

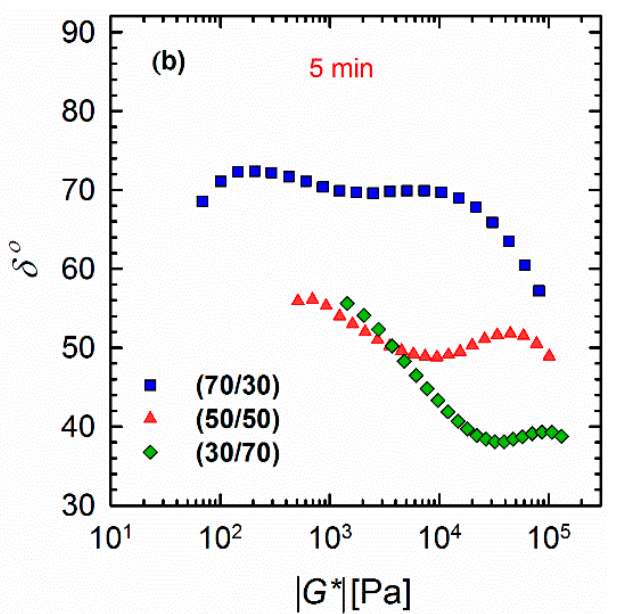

(b)

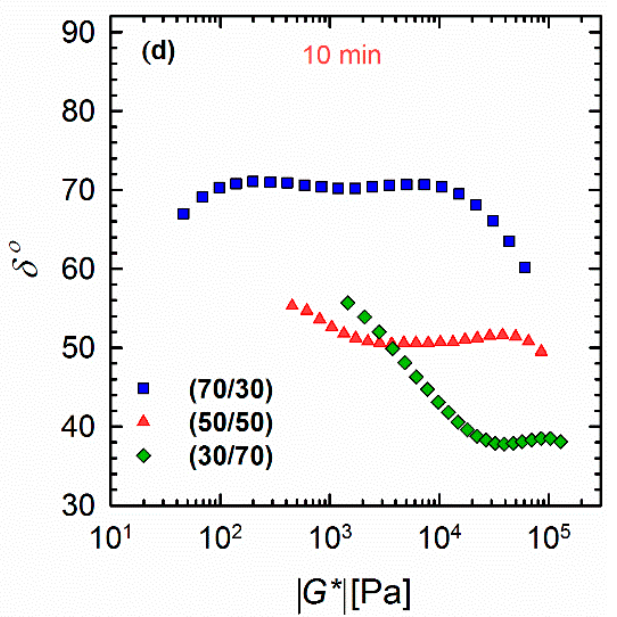

(d)

Figure 4. Van Gurp-Palmen plots of (a) neat polymers and (b-d) 70/30, 50/50, and 30/70 PLA/PVDF blends processed for (b) 5 , (c) 7.5 , and (d) $10 \mathrm{~min}$ at $200{ }^{\circ} \mathrm{C}$.

\subsection{Cole-Cole Plots}

A plot of $\eta^{\prime \prime}$ versus $\eta^{\prime}$, known as the Cole-Cole plot, is another tool that can be used to investigate the structures of phase-separated blends [33]. Parameters $\eta^{\prime \prime}$ and $\eta^{\prime}$ are imaginary and real contributions of the complex viscosity $\left(\eta^{*}=\eta^{\prime}-i \cdot \eta^{\prime \prime}\right)$. According to the literature $[30,31,34]$, polymers with monomodal molecular weight distributions show a typical arc-shape curve, where a double-arc shape indicates the droplet-matrix morphology. The first arc on the left-hand side of the plots (at low $\eta^{\prime}$ regions) is associated with relaxation of the polymers, whereas the arc on the right-hand side of the plots (at higher $\eta^{\prime}$ values) represents the relaxation of the droplets. The appearance of a tail at high $\eta^{\prime}$ values is known to be attributed to the interface, and indicates a co-continuous morphology. Taking this information into account, the blends under investigation in this study revealed different behaviors (Figure 5). Specifically, the 70/30 PLA/PVDF blend exhibited a slight hump that indicates the droplet-matrix morphology; by contrast, the 50/50 and 30/70 PLA/PVDF blends displayed a monotonic increase from low to high $\eta^{\prime}$ values. This increase could be caused by the nonlinear molecular structure of the PVDF, which makes these particular compositions cooperative segmental relaxations, as confirmed by analyses of the relaxation spectra (Figure 6). 


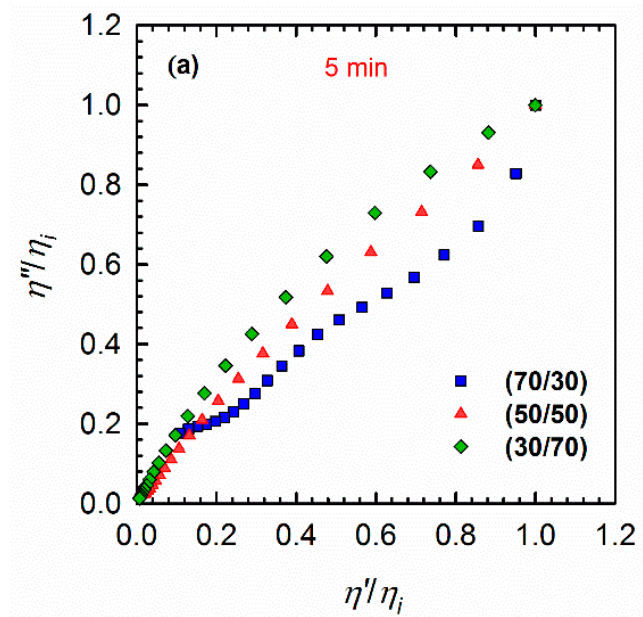

(a)

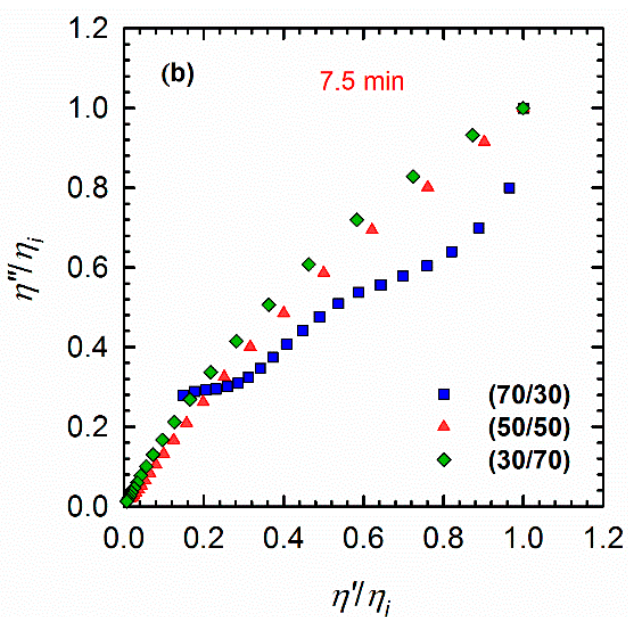

(b)

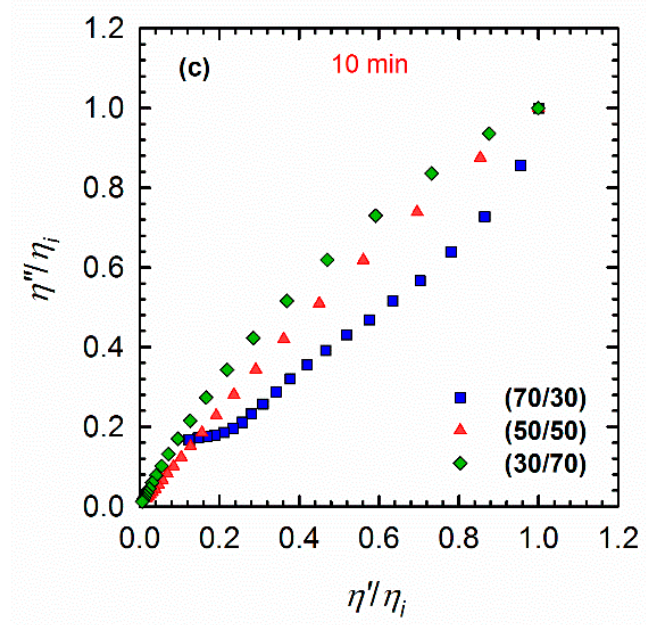

(c)

Figure 5. Cole-Cole plots of PLA/PVDF blends of different compositions processed for (a) $5 \mathrm{~min}$, (b) $7.5 \mathrm{~min}$, and (c) $10 \mathrm{~min}$. The plots are normalized relative to the values of $\eta^{\prime}$ and $\eta^{\prime \prime}$ of the respective initial viscosities $\eta_{i}$.

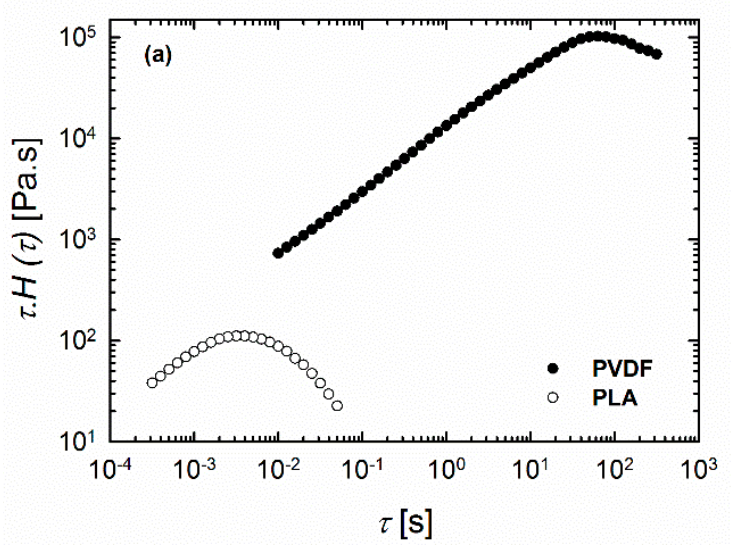

(a)

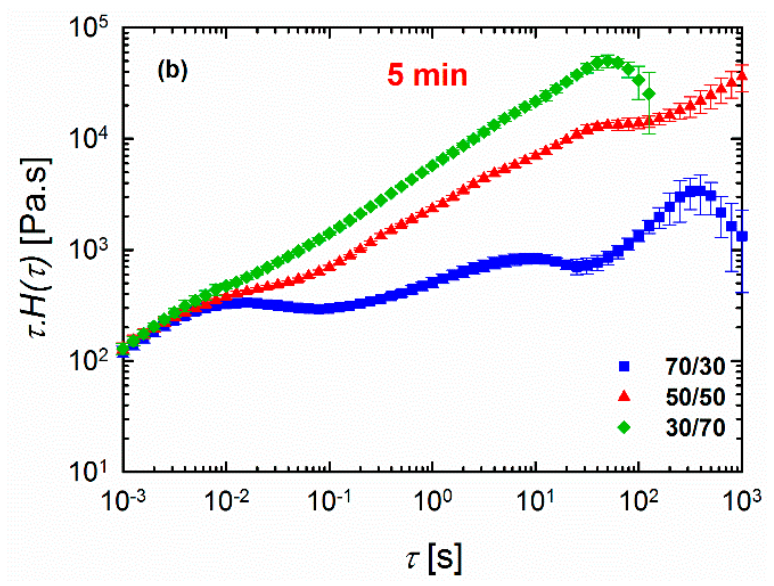

(b)

Figure 6. Cont. 


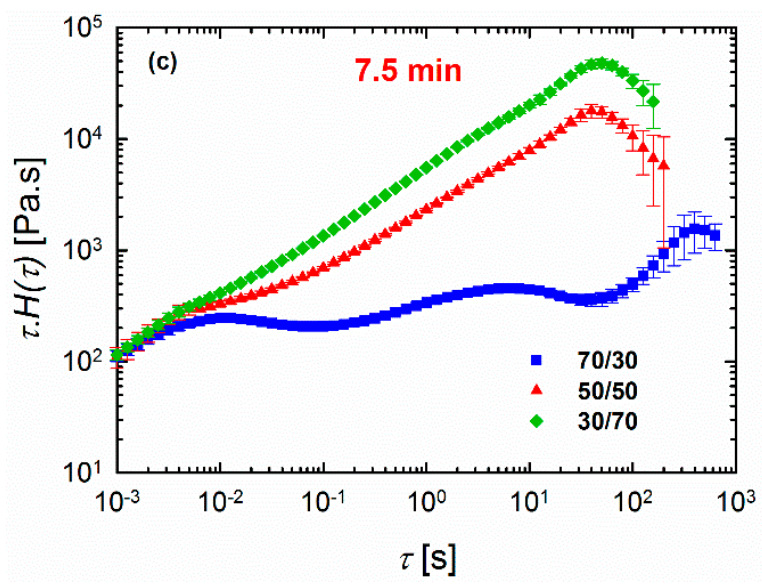

(c)

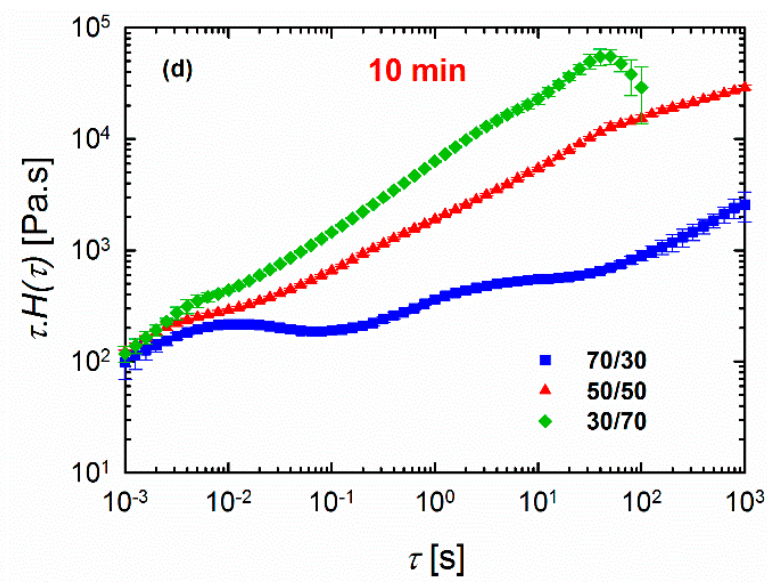

(d)

Figure 6. Weighted relaxation spectra of (a) neat polymers and (b-d) 70/30, 50/50, and 30/70 PLA/PVDF blends processed for (b) $5 \mathrm{~min}$, (c) $7.5 \mathrm{~min}$, and (d) $10 \mathrm{~min}$ at $200{ }^{\circ} \mathrm{C}$.

The Cole-Cole plots confirmed the results from the vGP plots, although the differences in the blends processed for different times (Figure 5) remained practically indistinguishable.

\subsection{Relaxation Spectra}

The differences in rheological responses originate from the relaxation of the polymers under shear conditions, and, consequently, it is worthwhile to examine the relaxation spectra of the blends. It has been shown that analyses based on continuous relaxation spectra could be very useful in the characterization of microstructures of materials with multiphase structures, such as blends $[24,35,36]$. Therefore, the weighted relaxation spectra of the polymers and blends processed at different times are plotted in Figure 6. It is immediately apparent that PLA relaxes quite fast at around $10^{-3}<\tau<10^{-2} \mathrm{~s}$, while PVDF relaxes quite slowly, with $\tau$ around $63 \mathrm{~s}$ (Figure 6a). It is clear that we have two polymers with completely different molecular structures and entanglement networks. Further, the blends also showed noticeably different behaviors. Among the blends examined, the 70/30 PLA/PVDF blend exhibited curve shapes that were quite different from the blends with 30/70 and 50/50 compositions. Three peaks were observed for this particular composition (70/30 PLA/PVDF). The peak at the very low relaxation time around $\tau=0.01 \mathrm{~s}$ corresponds to the relaxation time that is characteristic for PLA chains; the peak beyond $\tau \approx 100 \mathrm{~s}$ can be ascribed to the relaxation of PVDF. Moreover, the peak around $\tau \approx 5 \mathrm{~s}$ is associated with the form (shape) relaxation of PVDF droplets. The droplets of the minor phase undergo deformation during the oscillatory shear test; hence, they reserve the imposed energy. Therefore, the energy required to retract the deformed droplets to their equilibrium spherical shape (shape relaxation) causes an enhancement in the storage modulus (elasticity). Taking this information into account, a more pronounced shape relaxation process, and thus higher elasticity, can be expected for the systems with droplets that are more susceptible to deformation under force. In other words, blends with large viscosity ratios $K=\eta_{d} / \eta_{m}$ (where $\eta_{d}$ and $\eta_{m}$ are the viscosity of the dispersed phase and matrix, respectively) would have a lower amount of stored energy, and, thus, also shorter shape relaxation times as a result of the less deformed droplets. Therefore, as PVDF is a highly viscous phase, the droplets can hardly be deformed under the imposed dynamic oscillatory shear conditions, and, therefore, they exhibit relatively shorter relaxation times. A closer look at the SEM image of the 70/30 blend processed for $10 \mathrm{~min}$ (Figure 2c) reveals that the droplets are more in close-packed structures, which may promote cooperative relaxation processes and restrict interfacial relaxations. Hence, the second peak has become less pronounced in the 70/30 blend processed for $10 \mathrm{~min}$. In contrast to the systems with a large viscosity ratio, the systems that have a viscosity ratio smaller than unity, as in the case of the 30/70 PLA/PVDF blends, exhibit droplets with a much lower viscosity dominated by PLA, which will deform readily under the shear. That is, a longer time and 
more energy are required to pull back the deformed droplet. Interestingly, when the concentration of the highly crystalline PVDF was increased (i.e., the 30/70 PLA/PVDF blend), the material exhibited only a single characteristic relaxation peak at around $\tau \approx 50 \mathrm{~s}$, similar to that of the neat PVDF. Previous studies have reported that such behavior in blends where polymers do not relax independently can be attributed to the cooperative relaxation mechanism where only one peak appears in the relaxation spectrum, and this peak is similar to that observed for the single polymer [37-39]. According to Saito et al. [39], such cooperative relaxations in a binary system can occur when dynamic contacts exist between the two polymers. It has been also reported that such cooperative relaxation processes at the interface can be constrained by crystalline lamellas [40]. Therefore, increasing the fraction of the more crystalline (high viscosity) phase, PVDF in this case, enhances the restrictions at the interface, and, therefore, also the relaxations. It is worth noting that, in the case of the 50/50 blend (particularly after processing for $5 \mathrm{~min}$ and $10 \mathrm{~min}$ ), full relaxation was not observed. Consequently, no distinct peak could be observed, most likely as a result of the broad distribution of the domain phase and the very highly concentrated droplet morphologies (Figure 2c,d,f). In such a morphology, where a very populated droplet-shape minor phase exists (Figure 7), the interface cannot completely relax due to the constrained morphology. By contrast, in the case of the 50/50 blend processed for $7.5 \mathrm{~min}$, a more visible peak could be observed, probably due to the slight morphological reformations (Figure 2e).
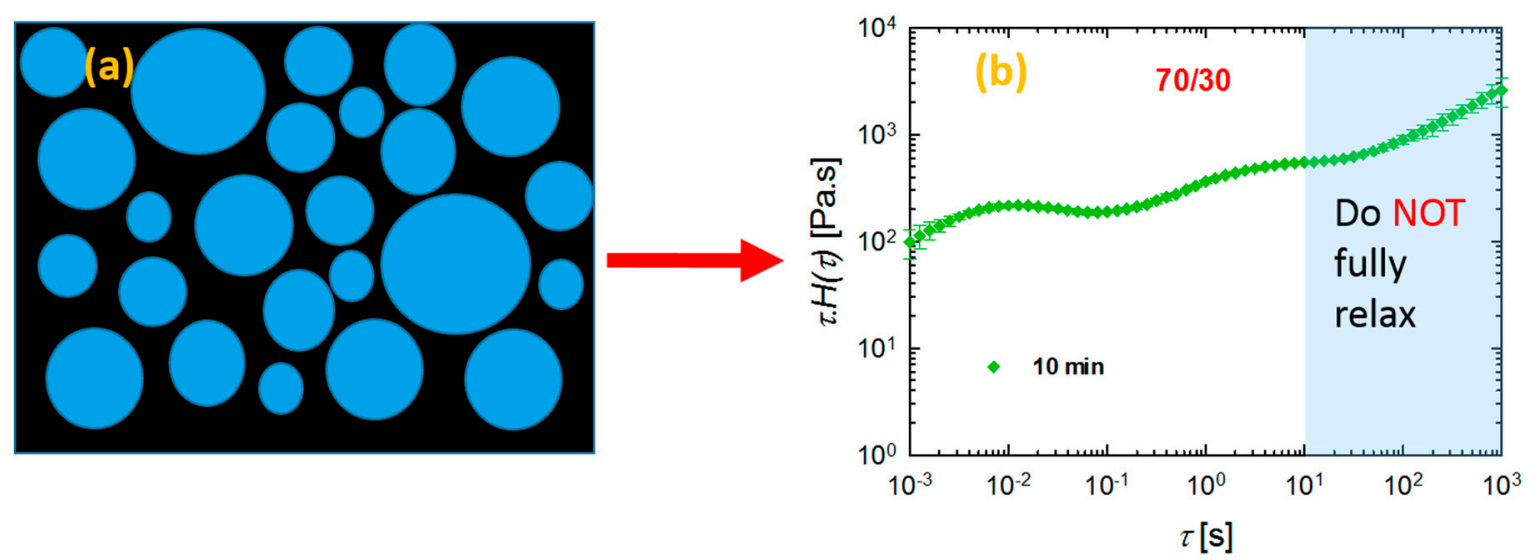

Figure 7. Schematic presentation of a relaxation spectra of a blend with a condensed morphology where the round-shaped domain phases are located in very close vicinity to one another as in the case of the $10 \mathrm{~min}$ processed (70/30) and $5 \mathrm{~min}$ and $10 \mathrm{~min}$ processed (50/50) PLA/PVDF blends.

\subsection{Interfacial Tension Analysis}

The relaxation spectra of the blends revealed the importance of the role of the interface in defining the non-terminal behaviour of the blends at longer times. It has been reported that the increase in elasticity of the blends could be related to the development of interfacial areas [41-43]. The Palierne model [44] has extensively been utilized to study the interfacial properties of the uncompatibilized and compatibilized blends [20,45-47]. However, it must be noted that the Palierne model is restricted to low concentrated systems with spherical morphologies with no droplet-droplet interactions [47]. Therefore, discrepancies between theoretical predictions and experimental calculations are inevitable. In this study, we employed the Palierne model (Equation (8)) to fit the complex moduli $\left|G^{*}(\omega)\right|$ of the $10 \mathrm{~min}$ processed blends in parallel with the Gramespacher and Meissner model [43] (Equation (9)), respectively, to examine the interfacial tensions $\alpha$. The Gramespacher and Meissner model was used based on the calculated relaxation spectra.

$$
\begin{gathered}
G_{b}^{*}(\omega)=G_{m}^{*}(\omega) \frac{1+3 \varnothing H^{*}(\omega)}{1-2 \varnothing H^{*}(\omega)}, \\
H^{*}(\omega)=\frac{4\left(\frac{\alpha}{R_{v}}\right)\left[2 G_{m}^{*}(\omega)+5 G_{d}^{*}(\omega)\right]+\left[G_{d}^{*}(\omega)-G_{m}^{*}(\omega)\right]\left[16 G_{m}^{*}(\omega)+19 G_{d}^{*}(\omega)\right]}{40\left(\frac{\alpha}{R_{v}}\right)\left[G_{m}^{*}(\omega)+G_{d}^{*}(\omega)\right]+\left[2 G_{d}^{*}(\omega)+3 G_{m}^{*}(\omega)\right]\left[16 G_{m}^{*}(\omega)+19 G_{d}^{*}(\omega)\right]}
\end{gathered}
$$




$$
\alpha=\left[\frac{R_{v} \eta_{m}}{\tau}\right]\left[\frac{(19 K+16)(2 K+3)}{40(K+1)}\right]\left[1+\varnothing\left(\frac{5(19 K+16)}{4(K+1)(2 K+3)}\right)\right]
$$

where $G_{b}^{*}(\omega), G_{m}^{*}(\omega)$, and $G_{d}^{*}(\omega)$ are the complex moduli of the blend, the matrix, and the dispersed phase at the angular frequency of $\omega$, respectively. $\varnothing, R_{v}, K$, and $\alpha$ are the volume fraction of the dispersed phase, the volume-averaged droplet size of the dispersed phase, the viscosity ratio, and the interfacial tension, respectively. The fitted results are shown in Figure 8. The interfacial tensions calculated from both the fitting (Equation (8)) and the relaxation spectra (Equation (9)) are summarized in Table 1.

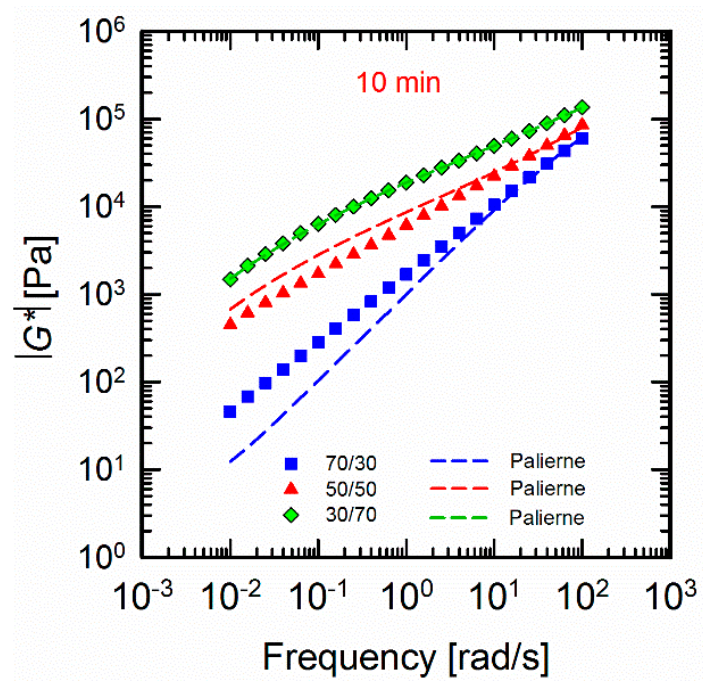

Figure 8. Palierne fittings of the 10 min processed (70/30), (50/50), and (30/70) PLA/PVDF blends measured at $200{ }^{\circ} \mathrm{C}$. The dashed lines represent the fitted results.

Table 1. The interfacial tension predicted by the Palierne model and the Gramespacher and Meissner model for the $10 \mathrm{~min}$ processed blends.

\begin{tabular}{|c|c|c|c|c|c|c|}
\hline Blend & $\begin{array}{c}* \\
\alpha[\mathrm{mN} / \mathrm{m}]^{\mathrm{a}}\end{array}$ & $\begin{array}{c}* \\
\alpha[\mathrm{mN} / \mathrm{m}] \\
b\end{array}$ & $\tau(s)$ & $\boldsymbol{R}_{\boldsymbol{v}}(\boldsymbol{\mu m})$ & $\boldsymbol{R}_{n}(\boldsymbol{\mu \mathrm { m }})$ & D \\
\hline$(70 / 30)$ & 14.44 & 86.27 & 5 & $0.84 \pm 0.03$ & $0.48 \pm 0.04$ & $1.76 \pm 0.17$ \\
\hline$(50 / 50)$ & 25.57 & 72.80 & 50 & $1.19 \pm 0.18$ & $0.62 \pm 0.08$ & $1.93 \pm 0.21$ \\
\hline$(30 / 70)$ & 5.12 & 9.86 & 50 & $0.21 \pm 0.00$ & $0.11 \pm 0.00$ & $1.86 \pm 0.12$ \\
\hline
\end{tabular}

${ }^{a}$ calculated from fitting the Palierne model; ${ }^{b}$ calculated from weighted relaxation spectra (the Gramespacher and Meissner model); ${ }^{*}$ for calculation of the viscosity ratio $K$, the Carreau-Yasuda model was used to fit the viscosity of the neat polymers since PVDF did not show the plateau behaviour (Figure S3).

It can be observed that the Palierne model fails to predict the moduli of the (70/30) and (50/50) blends. It has also been reported that the Palierne model and its derivatives can be used for the systems with droplet distributions less than 2 , where the system is not highly concentrated as in the case of (70/30) and (50/50). As we discused earlier, the $10 \mathrm{~min}$ mixed (70/30) and (50/50) blends showed highly populated morphologies that may encourage the droplet-droplet contacts, and, as a result, this can affect the calculations and cause uncertainty in the fitting results. It can also be seen that when PLA is the minor phase in (30/70) PLA/PVDF blends the model fits well. This reflects the narrow droplet size distributions in this particular composition. It can be inferred that the high viscos PVDF matrix immobilized the PLA droplets where a lower probability of the droplet-droplet interactions is provided. Instead, the low viscosity ratio has provoked the droplet breakup. As a result, morphologies with smaller droplets and larger surface areas are obtained. The large values of interfacial tensions obtained along with the ill-fitted results indicated that such models cannot be used to predict the interfacial tensions of the highly populated droplet morphologies. The estimations, 
however controversial, confirmed the lower interfacial tensions for the composition where the higher viscos phase PVDF is the matrix and the low viscos phase PLA, the dispersed phase.

Although the predicted values are rough estimations and, as explained above, they are affected by simplifications and droplet size measurements, they can be used as complementary results confirming the effect of the composition ratio and the viscosity ratio on the viscoelastic response and morphological evolutions of the blends. It must be also taken into account that the blends exhibited a somewhat cooperative relaxation process, which could influence the final calculated values.

\subsection{Dynamic Mechanical Analysis}

Thus far, we have focused on probing the importance of chain mobility and dynamics. At this point, it is of interest to observe the molecular dynamics of the polymers at different temperatures, and one promising method of doing so utilizes the DMA tests. The storage modulus $E^{\prime}$ and the loss factor ( $\tan \delta=E^{\prime \prime} / E^{\prime}$ where $E^{\prime \prime}$ and $E^{\prime}$ are the loss and storage moduli, respectively) values of the blends processed for $10 \mathrm{~min}$ as a function of temperature are plotted from -60 to $140{ }^{\circ} \mathrm{C}$ in Figure 9. According to literature reports, PVDF has a glass transition temperature $\mathrm{Tg}$ of around $-30^{\circ} \mathrm{C}$ [48-50]. Studies have shown that $\tan \delta$ peak around -30 and $100^{\circ} \mathrm{C}$ are associated with amorphous ( $\beta$-relaxation) and crystalline ( $\alpha$-relaxation) segmental motions, respectively [51-55]. In Figure $9 a$, a rapid decrease in storage modulus around $\left(70-80^{\circ} \mathrm{C}\right)$ is attributed to the glass transition temperature of the blends, which further rises again around $90-110^{\circ} \mathrm{C}$. This increase in storage modulus at a high temperature corresponds to the cold crystallization of PLA where, at a lower PLA concentration (30/70), it gradually fades away. A further decrease in modulus also indicates the onset of melting and softening of the blends $[56,57]$. Figure $9 \mathrm{~b}$ reveals that the $\beta$-relaxation peak is more significant in the case of the $30 / 70$ PLA/PVDF blend. Such $\beta$-molecular rearrangements are known to govern the crystal growth and nucleation process in a system $[58,59]$. By contrast, the peak around $76{ }^{\circ} \mathrm{C}$ corresponds to the $\mathrm{Tg}$ of PLA. It should be noted that the differences between the reported and measured values of $\mathrm{Tg}$ could be caused by the differences in heating rates, as well as the fact that during DMA tests, a force is imposed on the samples. As expected, it can be seen that the height of the peak associated with the $\mathrm{Tg}$ of PLA increases gradually as the PLA content increases. Interestingly, the $\alpha$-relaxation peaks can only be seen in the case of the 70/30 and 30/70 PLA/PVDF blends, and no such peak is observed for the 50/50 blend. Instead, this blend exhibits a broader peak at the Tg of PLA. This result can be explained by the weighted relaxation spectra, where the 50/50 blend did not display a distinct peak at high relaxation times. As explained in the previous section, since this particular composition has the populated droplet-shape domain phase, the interface is constrained during the relaxation process. Therefore, the crystalline segments of PVDF cannot relax completely.

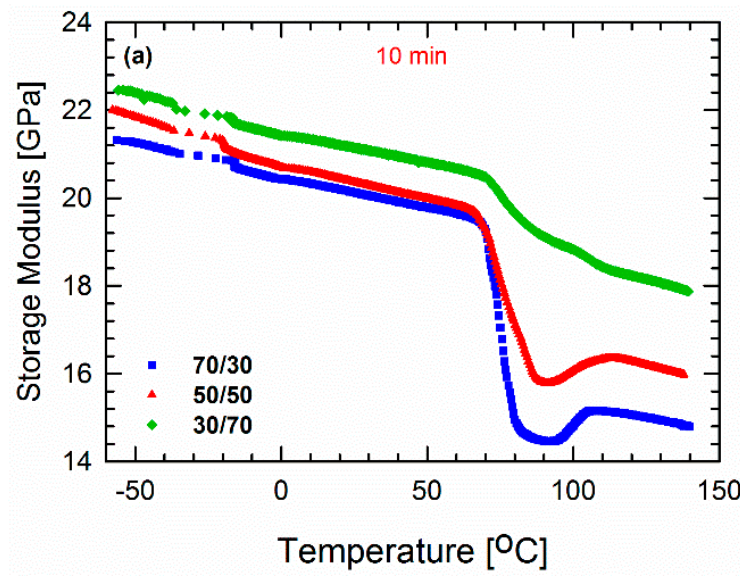

(a)

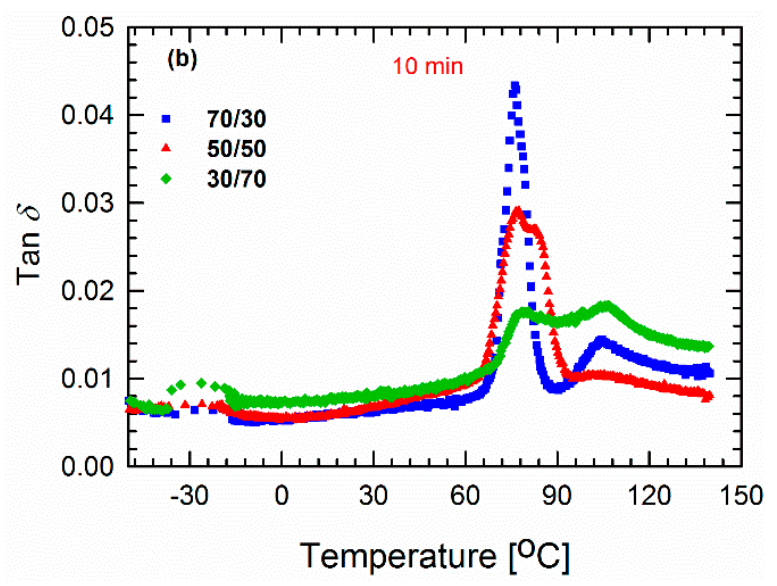

(b)

Figure 9. (a) Storage moduli $E^{\prime}$ and (b) $\tan \delta$ values of blends processed for $10 \mathrm{~min}$ as a function of temperature $\left(-60\right.$ to $\left.140{ }^{\circ} \mathrm{C}\right)$ and measured at a frequency of $1 \mathrm{~Hz}$. 


\section{Conclusions}

In this study, linear dynamic oscillatory tests were exploited to unravel the morphologies of PLA/PVDF blends at three different ratios (30/70, 50/50 and 70/30) and their dependency on the processing time. The rheological analyses based on SAOS tests revealed, as expected, elasticity enhancements in systems with increased PVDF content owing to the significantly higher viscosity of neat PVDF when compared to that of neat PLA. The analysis also revealed that, since the blends were not compatibilized, they underwent changes during the processing. The SEM images of the blends mirrored the rheological responses. In blends with the higher viscosity phase PVDF as the minor phase, the large viscosity ratio prevented the break-up process, and PVDF droplets instead coalesced during the processing, causing a slight drop in elasticity. In order to better understand the behaviors of the blends under shear tests, continuous relaxation spectra were calculated. The weighted relaxation spectra were quite useful in unraveling the microstructures of the blends. PVDF was found to have a large relaxation time, most likely arising from the presence of entangled networks. Therefore, in PVDF-enriched PLA/PVDF blends (i.e., 30/70 ratio), the spectra were affected by the very slow relaxation of PVDF, and exhibited a cooperative relaxation mechanism; consequently, only a single relaxation peak could be observed. In PLA-enriched PLA/PVDF blends (i.e., 70/30 ratio), the relaxation peak associated with the relaxation of PVDF was broad and found between 5 and $10 \mathrm{~s}$. This result was attributed to the broad droplet distribution of the blend, since the high viscosity PVDF droplets are difficult to break into smaller ones. The analysis also showed that highly concentrated structures, e.g., those in the 50/50 blend, exhibited relaxation spectra that increased progressively, indicating a lack of full relaxation. This feature also manifested in the DMA results, where $\alpha$-relaxation associated with the crystalline motions around $100{ }^{\circ} \mathrm{C}$ was reduced in the case of the $50 / 50$ blend processed for $10 \mathrm{~min}$. Generally, analyses based on relaxation mechanisms of the blends could give better insight into their microstructures. Therefore, we can conclude that, for immiscible polymer blends, an understanding of the correlation between a processing-driven morphology and rheological properties is crucial to gain knowledge on processibility and product development.

Supplementary Materials: The following are available online at http:/ /www.mdpi.com/1996-1944/11/12/2450/s1, Figure S1: Loss (viscous) moduli $G^{\prime}(\omega)$ of (a) neat polymers and (b-d) (70/30), (50/50), and (30/70) PLA/PVDF blends processed for different times as a function of frequency from 0.01 to $100 \mathrm{rad} / \mathrm{s}$ at a strain amplitude of $0.5 \%$ and a temperature of $200^{\circ} \mathrm{C}$ under a nitrogen atmosphere, Figure S2: Complex viscosities $\left|\eta^{*}(\omega)\right|$ of the (70/30), (50/50), and (30/70) PLA/PVDF blends processed for (a) 5, (b) 7.5, and (c) $10 \mathrm{~min}$ as a function of frequency from 0.01 to $100 \mathrm{rad} / \mathrm{s}$ at a strain amplitude of $0.5 \%$ and a temperature of $200{ }^{\circ} \mathrm{C}$ under a nitrogen atmosphere, Figure S3: Complex viscosity of the neat polymers at a strain amplitude of $0.5 \%$ and a temperature of $200{ }^{\circ} \mathrm{C}$ under a nitrogen atmosphere. A Carreau-Yasuda fitting was utilized to obtain the zero-shear viscosity values required for calculation of the viscosity ratio.

Author Contributions: R.S. and S.S.R. designed the concept, F.J.S. did the spectrum calculations and analysis, V.O. processed and characterized the blends, R.S. performed the rheological experiments, all the authors discussed, edited and reviewed the manuscript.

Funding: The authors would like to thank the Council for Scientific and Industrial Research (HGER20S) and the Department of Science and Technology (HGERA8X) for financial support.

Conflicts of Interest: The authors declare no conflict of interest. The funders had no role in the design of the study; in the collection, analyses, or interpretation of data; in the writing of the manuscript, and in the decision to publish the results.

\section{References}

1. Paul, D.; Walsh, D.; Higgins, J. Polymer Blends and Mixtures; Springer: Berlin, Germany, 1985.

2. Salehiyan, R.; Song, H.Y.; Hyun, K. Nonlinear behavior of PP/PS blends with and without clay under large amplitude oscillatory shear (LAOS) flow. Korea. Aust. Rheol. J. 2015, 27, 95-103. [CrossRef]

3. Ziegler, V.; Wolf, B.A. Viscosity and morphology of the two-phase system PDMS/P (DMS-ran-MPS). J. Rheol. 1999, 43, 1033-1045. [CrossRef]

4. Jafari, S.-H.; Hesabi, M.-N.; Khonakdar, H.A.; Asl-Rahimi, M. Correlation of rheology and morphology and estimation of interfacial tension of immiscible COC/EVA blends. J. Polym. Res. 2011, 18, 821-831. [CrossRef] 
5. Utracki, L. On the viscosity-concentration dependence of immiscible polymer blends. J. Rheol. 1991, 35, 1615-1637. [CrossRef]

6. Van Puyvelde, P.; Moldenaers, P. Rheology and morphology development in immiscible polymer blends. Rheol. Rev. 2005, 2005, 101.

7. Khalili, R.; Jafari, S.H.; Saeb, M.R.; Khonakdar, H.A.; Wagenknecht, U.; Heinrich, G. Toward in situ compatibilization of polyolefin ternary blends through morphological manipulations. Macromol. Mater. Eng. 2014, 299, 1197-1212. [CrossRef]

8. Yousfi, M.; Soulestin, J.; Vergnes, B.; Lacrampe, M.F.; Krawczak, P. Compatibilization of immiscible polymer blends by organoclay: Effect of nanofiller or organo-modifier? Macromol. Mater. Eng. 2013, 298, 757-770. [CrossRef]

9. Salehiyan, R.; Choi, W.J.; Lee, J.H.; Hyun, K. Effects of mixing protocol and mixing time on viscoelasticity of compatibilized PP/PS blends. Korea Aust. Rheol. J. 2014, 26, 311-318. [CrossRef]

10. Wang, Y.; Zhang, Q.; Fu, Q. Compatibilization of immiscible poly (propylene)/polystyrene blends using clay. Macromol. Rapid Commun. 2003, 24, 231-235. [CrossRef]

11. Cho, S.; Hong, J.S.; Lee, S.J.; Ahn, K.H.; Covas, J.A.; Maia, J.M. Morphology and rheology of polypropylene/polystyrene/clay nanocomposites in batch and continuous melt mixing processes. Macromol. Mater. Eng. 2011, 296, 341-348. [CrossRef]

12. Jiang, G.; Huang, H.-X.; Chen, Z.-K. Rheological responses and morphology of polylactide/linear low density polyethylene blends produced by different mixing type. Polym. Plast. Technol. Eng. 2011, 50, 1035-1039. [CrossRef]

13. Salehiyan, R.; Ray, S.S. Influence of nanoclay localization on structure-property relationships of polylactide-based biodegradable blend nanocomposites. Macromol. Mater. Eng. 2018, 303, 1800134. [CrossRef]

14. Nofar, M.; Maani, A.; Sojoudi, H.; Heuzey, M.C.; Carreau, P.J. Interfacial and rheological properties of PLA/PBAT and PLA/PBSA blends and their morphological stability under shear flow. J. Rheol. 2015, 59, 317-333. [CrossRef]

15. Nam, J.Y.; Okamoto, M.; Okamoto, H.; Nakano, M.; Usuki, A.; Matsuda, M. Morphology and crystallization kinetics in a mixture of low-molecular weight aliphatic amide and polylactide. Polymer 2006, 47, 1340-1347. [CrossRef]

16. Nofar, M.; Heuzey, M.C.; Carreau, P.J.; Kamal, M.R. Effects of nanoclay and its localization on the morphology stabilization of PLA/PBAT blends under shear flow. Polymer 2016, 98, 353-364. [CrossRef]

17. Wu, D.; Zhang, Y.; Zhang, M.; Zhou, W. Phase behavior and its viscoelastic response of polylactide/poly(E-caprolactone) blend. Eur. Polym. J. 2008, 44, 2171-2183. [CrossRef]

18. Bai, L.; He, S.; Fruehwirth, J.W.; Stein, A.; Macosko, C.W.; Cheng, X. Localizing graphene at the interface of cocontinuous polymer blends: Morphology, rheology, and conductivity of cocontinuous conductive polymer composites. J. Rheol. 2017, 61, 575-587. [CrossRef]

19. Deng, Y.; Thomas, N.L. Blending poly (butylene succinate) with poly (lactic acid): Ductility and phase inversion effects. Eur. Polym. J. 2015, 71, 534-546. [CrossRef]

20. Salehiyan, R.; Ray, S.S.; Bandyopadhyay, J.; Ojijo, V. The distribution of nanoclay particles at the interface and their influence on the microstructure development and rheological properties of reactively processed biodegradable polylactide/poly(butylene succinate) blend nanocomposites. Polymers 2017, 9, 350. [CrossRef]

21. Salehiyan, R.; Ray, S.S.; Ojijo, V. Process Driven Morphology Developement and Crystallization Behaviour of Immiscible Polylactic acid/Polyvinylidene fluoride (PLA/PVDF) blends. Macromol. Mater. Eng. 2018, 1800349. [CrossRef]

22. Xie, Q.; Ke, K.; Jiang, W.R.; Yang, W.; Liu, Z.Y.; Xie, B.H.; Yang, M.B. Role of poly (lactic acid) in the phase transition of poly (vinylidene fluoride) under uniaxial stretching. J. Appl. Polym. Sci. 2013, 129, 1686-1696. [CrossRef]

23. Wang, H.; Yang, X.; Fu, Z.; Zhao, X.; Li, Y.; Li, J. Rheology of nanosilica-compatibilized immiscible polymer blends: Formation of a "heterogeneous network" facilitated by interfacially anchored hybrid nanosilica. Macromolecules 2017, 50, 9494-9506. [CrossRef]

24. Stadler, F.J.; Bailly, C. A new method for the calculation of continuous relaxation spectra from dynamic-mechanical data. Rheol. Acta 2009, 48, 33-49. [CrossRef] 
25. Baumgaertel, M.; Winter, H.H. Determination of discrete relaxation and retardation time spectra from dynamic mechanical data. Rheol. Acta 1989, 28, 511-519. [CrossRef]

26. Stadler, F.J. Effect of incomplete datasets on the calculation of continuous relaxation spectra from dynamic-mechanical data. Rheol. Acta 2010, 49, 1041-1057. [CrossRef]

27. Kong, M.; Huang, Y.; Lv, Y.; Wang, S.; Yang, Q.; Li, G. Flow-induced morphological instability in nanosilica-filled polyamide 6/polystyrene blends. Polymer 2014, 55, 4348-4357. [CrossRef]

28. Fenouillot, F.; Cassagnau, P.; Majesté, J.C. Uneven distribution of nanoparticles in immiscible fluids: Morphology development in polymer blends. Polymer 2009, 50, 1333-1350. [CrossRef]

29. Gonzalez-Nunez, R.; Favis, B.; Carreau, P.; Lavallee, C. Factors influencing the formation of elongated morphologies in immiscible polymer blends during melt processing. Polym. Eng. Sci. 1993, 33, 851-859. [CrossRef]

30. Li, R.; Yu, W.; Zhou, C. Rheological characterization of droplet-matrix versus co-continuous morphology. J. Macromol. Sci. B 2006, 45, 889-898. [CrossRef]

31. López-Barrón, C.R.; Macosko, C.W. Rheology of compatibilized immiscible blends with droplet-matrix and cocontinuous morphologies during coarsening. J. Rheol. 2014, 58, 1935-1953. [CrossRef]

32. Liu, D.; Li, W.; Zhang, N.; Huang, T.; Yang, J.; Wang, Y. Graphite oxide-driven miscibility in PVDF/PMMA blends: Assessment through dynamic rheology method. Eur. Polym. J. 2017, 96, 232-247. [CrossRef]

33. Ajji, A.; Choplin, L.; Prud Homme, R.E. Rheology of polystyrene/poly(vinyl methyl ether)blends near the phase transition. J. Polym. Sci. B Polym. Phys. 1991, 29, 1573-1578. [CrossRef]

34. Ding, Y.; Lu, B.; Wang, P.; Wang, G.; Ji, J. PLA-PBAT-PLA tri-block copolymers: Effective compatibilizers for promotion of the mechanical and rheological properties of pla/pbat blends. Polym. Degrad. Stab. 2018, 147, 41-48. [CrossRef]

35. López-Barrón, C.R.; Macosko, C.W. Rheological and morphological study of cocontinuous polymer blends during coarsening. J. Rheol. 2012, 56, 1315-1334. [CrossRef]

36. Soo Cho, K.; Woo Park, G. Fixed-point iteration for relaxation spectrum from dynamic mechanical data. J. Rheol. 2013, 57, 647-678. [CrossRef]

37. Saito, H.; Takahashi, M.; Inoue, T. Cooperative chain relaxation in miscible polymer blends. J. Polym. Sci. $B$ Polym. Phys. 1988, 26, 1761-1768. [CrossRef]

38. Saito, H.; Takahashi, M.; Inoue, T. Chain relaxation behavior in single-phase mixtures of dissimilar polymers. Macromolecules 1991, 24, 6536-6538. [CrossRef]

39. Saito, H.; Miyashita, H.; Inoue, T. Cooperative chain relaxation in a single-phase mixture of dissimilar polymers: Definition and implication of the cooperativity. Macromolecules 1992, 25, 1824-1827. [CrossRef]

40. Mijovic, J.; Sy, J.-W.; Kwei, T. Reorientational dynamics of dipoles in poly (vinylidene fluoride)/poly (methyl methacrylate)(PVDF/PMMA) blends by dielectric spectroscopy. Macromolecules 1997, 30, 3042-3050. [CrossRef]

41. Bousmina, M. Effect of interfacial tension on linear viscoelastic behavior of immiscible polymer blends. Rheol. Acta 1999, 38, 251-254. [CrossRef]

42. Graebling, D.; Muller, R.; Palierne, J. Linear viscoelasticity of incompatible polymer blends in the melt in relation with interfacial properties. J. Phys. IV 1993, 3, 1525-1534. [CrossRef]

43. Gramespacher, H.; Meissner, J. Interfacial tension between polymer melts measured by shear oscillations of their blends. J. Rheol. 1992, 36, 1127-1141. [CrossRef]

44. Palierne, J. Linear rheology of viscoelastic emulsions with interfacial tension. Acta. 1990, 29, $204-214$. [CrossRef]

45. Gui, Z.Y.; Wang, H.R.; Gao, Y.; Lu, C.; Cheng, S.J. Morphology and melt rheology of biodegradable poly (lactic acid)/poly (butylene succinate adipate) blends: effect of blend compositions. Iran. Polym. J. 2012, 21, 81-89. [CrossRef]

46. Kwon, M.K.; Cho, K.S. Analysis of the Palierne model by relaxation time spectrum. Korea Aust. Rheol. J. 2016, 28, 23-31. [CrossRef]

47. Maani, A.; Blais, B.; Heuzey, M.C.; Carreau, P.J. Rheological and morphological properties of reactively compatibilized thermoplastic olefin (TPO) blends. J. Rheol. 2012, 56, 625-647. [CrossRef]

48. Wang, H.; Dong, W.; Li, Y. Compatibilization of immiscible polymer blends using in situ formed janus nanomicelles by reactive blending. ACS Macro Lett. 2015, 4, 1398-1403. [CrossRef] 
49. Wang, H.; Fu, Z.; Dong, W.; Li, Y.; Li, J. Formation of interfacial janus nanomicelles by reactive blending and their compatibilization effects on immiscible polymer blends. J. Phys. Chem. B 2016, 120, 9240-9252. [CrossRef] [PubMed]

50. Wang, H.; Fu, Z.; Zhao, X.; Li, Y.; Li, J. Reactive nanoparticles compatibilized immiscible polymer blends: Synthesis of reactive $\mathrm{SiO}_{2}$ with long poly (methyl methacrylate) chains and the in situ formation of janus $\mathrm{SiO}_{2}$ nanoparticles anchored exclusively at the interface. ACS Appl. Mater. Interfaces 2017, 9, 14358-14370. [CrossRef] [PubMed]

51. Pawde, S.; Bhat, N. Thermal analysis of poly (vinylidene fluoride)(PVDF) in composites with polypyrrole (PPY). J. Appl. Polym. Sci. 1994, 54, 201-205. [CrossRef]

52. Sencadas, V.; Lanceros-Mendez, S.; Mano, J. Characterization of poled and non-poled $\beta$-pvdf films using thermal analysis techniques. Thermochim. Acta 2004, 424, 201-207. [CrossRef]

53. Vidhate, S.; Shaito, A.; Chung, J.; D'Souza, N.A. Crystallization, mechanical, and rheological behavior of polyvinylidene fluoride/carbon nanofiber composites. J. Appl. Polym. Sci. 2009, 112, 254-260. [CrossRef]

54. Mano, J.; Sencadas, V.; Costa, A.M.; Lanceros-Méndez, S. Dynamic mechanical analysis and creep behaviour of $\beta$-pvdf films. Mater. Sci. Eng. A 2004, 370, 336-340. [CrossRef]

55. Mofokeng, T.G.; Luyt, A.S.; Pavlović, V.P.; Pavlović, V.B.; Dudić, D.; Vlahović, B.; Djoković, V. Ferroelectric nanocomposites of polyvinylidene fluoride/polymethyl methacrylate blend and batio3 particles: Fabrication of $\beta$-crystal polymorph rich matrix through mechanical activation of the filler. J. Appl. Phys. 2014, 115, 084109. [CrossRef]

56. Mofokeng, J.P.; Luyt, A.S.; Tábi, T.; Kovács, J. Comparison of injection moulded, natural fibre-reinforced composites with PP and PLA as matrices. J. Thermoplast. Compos. Mater. 2012, 25, 927-948. [CrossRef]

57. Salehiyan, R.; Yussuf, A.A.; Hanani, N.F.; Hassan, A.; Akbari, A. Polylactic acid/polycaprolactone nanocomposite: Influence of montmorillonite and impact modifier on mechanical, thermal, and morphological properties. J. Elastomers Plast. 2015, 47, 69-87. [CrossRef]

58. Okamoto, N.; Oguni, M. Discovery of crystal nucleation proceeding much below the glass transition temperature in a supercooled liquid. Solid State Commun. 1996, 99, 53-56. [CrossRef]

59. Hikima, T.; Hanaya, M.; Oguni, M. Microscopic observation of a peculiar crystallization in the glass transition region and $\beta$-process as potentially controlling the growth rate in triphenylethylene. J. Mol. Struct. 1999, 479, 245-250. [CrossRef] 